\title{
Establishing the safety of novel bio-based cellulose nanomaterials for commercialization
}

\author{
Authors: Ong, K.J. ${ }^{1}$, Shatkin, JA. ${ }^{1}$, Nelson, K. ${ }^{2}$, Ede, J. ${ }^{1}$, Retsina, T. ${ }^{2}$ \\ ${ }^{1}$ Vireo Advisors LLC, PO Box 51368, Boston, MA, 02205, USA \\ ${ }^{2}$ American Process Inc., 750 Piedmont Avenue NE, Atlanta, GA, 30308, USA
}




\section{Abstract}

In the commercial development of novel nanoscale materials, a proactive approach toward safe commercialization requires assessment of material safety for manufacturing, in product use and for environmental impacts. The goal of this study was to design an industrially-relevant testing strategy and develop key data on lignin-coated cellulose nanomaterials to evaluate their safety before widescale market introduction and subsequent commercialization. The testing plan developed to evaluate BioPlus ${ }^{\circledR}$ lignin-coated fibrils (L-CNF) and BioPlus ${ }^{\circledR}$ lignin-coated crystals (L-CNC) considered a range of potential uses, and employed a variety of standard and tailored protocols to characterize physico-chemical properties, human health effects and environmental fate and toxicity. For human health studies, acute oral toxicity testing as well as dermal and eye irritation studies were completed. Results reveal no oral, dermal or ocular toxicity following L-CNC and L-CNF exposure at the highest doses tested. Testing conducted to evaluate potential environmental effects included aquatic toxicity testing of bacteria (Vibrio fisheri), algae (Pseudokirchneriella subcapitata), invertebrates (Daphnia magna), and vertebrates (Danio rerio). A unique aspect of the study was that in general, testing was performed at environmentally relevant concentrations. Virtually no toxic effects were reported for either L-CNC or L-CNF in these tests, even at artificially high concentrations that could not feasibly occur in the environment. Together with published studies examining the effects of related and conventional substances, these results demonstrate that L-CNC and L-CNF are relatively non-toxic for the broad range of endpoints considered, much like their conventional cellulosic counterparts. These results were anticipated, due to the ubiquity of cellulose in commerce and in the environment, however publication of such negative results is rare, yet critically important to further understanding of the disposition of commercially relevant nanoscale materials.

\section{Keywords}

Cellulose Nanomaterials, Cellulose Nanocrystals, Cellulose Nanofibrils, Nanocellulose, Nanomaterials Commercialization, Safety, Environmental Health and Safety

\section{Introduction}

The commercialization of nanomaterials (NMs) offers opportunities for the use of safer materials that provide novel or improved properties. However, due to their novelty, the need to be proactive and demonstrate safety across the product life cycle in advance of their use in products is essential for customer, user and stakeholder confidence. Until reliable methods are developed to predict the toxicity of a NM, thorough safety testing must be completed.

The NMs industry is growing rapidly and innovative NMs are enabling advances in almost every sector, including environmental remediation, medical applications, consumer products, agriculture, food and feed and many more. One of these promising classes of NMs is cellulose nanomaterials (CNs), or nanocellulose, which are bio-based, nano-sized cellulose materials derived from a wide range of renewable resources including wood, cotton, and bacteria. Cellulose is a major structural component in plants and can be found in some marine chordates, algae, bacteria, and protozoa. CNs can be made in cellulose nanocrystal (CNC) form, that have stiff rod-like forms with aspects ratios of $\sim 5-30$, or as cellulose nanofibers (CNFs), which are generally larger and have flexible, fibril-like morphologies with high aspect ratios of $\sim 10-100$ (Moon et al. 2016). Moving towards materials such as CNs that use renewable biological resources to support a 'bio-based economy' is a goal of many 
governments, international organizations, and private groups (Exec Order No. 13693, 80 FR 15869, 2015). Bio-based products promise to be drivers of innovation, economy, and sustainability. The European bioeconomy alone created net sales of $\sim 2$ trillion euros and employed over 17 million people in 2013 (Ronzon et al. 2016).

Cellulose nanomaterials are high strength and lightweight materials with a multitude of applications. This includes uses in traditional forest industry sectors such as paper and packaging, in nontraditional sectors such as construction and vehicles, and for completely novel applications, such as flexible electronics (Shatkin et al. 2014). CNs have many sustainable features: they derive from abundant renewable resources, are compostable, can replace toxic or less sustainable materials, and can provide for better environmental performance in the use phase. It is important to be proactive in the study of new and emerging materials prior to mass production to suitably demonstrate their safety in regard to the public, the environment, or those working directly with them. Studies assessing the potential for exposure during the product life cycle from manufacturing through to end-of-life help identify areas to prioritize for testing (Shatkin 2012).

A recent study assessed the availability of safety data of CNs in the context of Safety Data Sheet requirements and identified gaps for CNs in categories of human health and environmental safety, preventing hazard classification according to the Globally Harmonized System for these materials (Shatkin et al. 2016). There has been an increasing amount of safety data published on CNs but there are still data gaps. It is important to characterize the pchem properties of CNs to allow for better modeling of these materials and help connect these characteristics with their fate and toxicity, thus reducing the need to perform future in vitro or in vivo toxicology experiments. Consideration of material disposition during the use and disposal stages are important considerations for overall product safety, such as material biodegradability.

American Process Inc.'s (API's) patented AVAP® technology offers commercially-scalable production of CNs with flexibility in final product morphology ( $\mathrm{CN}$ fibrils or CN crystals) and surface properties (hydrophilic or nonpolar, more hydrophobic) that can serve the wide variety of emerging end-use market segments under the brand name BioPlus ${ }^{\circledR}$ (Nelson and Retsina, 2014). The AVAP process uses sulfur dioxide and ethanol to remove hemicelluloses, lignin, and the amorphous regions of cellulose from biomass. The final $\mathrm{CN}$ product morphology (CNF or $\mathrm{CNC}$ ) is controlled by the time and temperature (i.e. severity) of chemical treatment. The resulting fiber is then bleached using a conventional industrial process to remove any residual biomass components such as lignin in order to obtain pure cellulose. Alternatively, the fiber is treated using a proprietary method that deposits lignin onto the surface of the weakly associated fibrils or crystals. Mechanical energy is then applied to liberate the individual CN particles (Nelson et al. 2016).

The novel nonpolar lignin-coated varieties, BioPlus lignin-coated fibrils (L-CNF) and BioPlus lignin-coated crystals (L-CNC) address a well-known limitation to the commercial utilization of conventional pure cellulose CNs. CNs are attractive renewable materials for reinforcing and lightweighting plastic composites because of its exceptionally high strength, low density, and high surface area. However, the compatibility and dispersibility of conventional CNs in plastics is poor because of the hydroxyl groups covering the cellulose surface. Most plastics are nonpolar and hydrophobic in nature. While, L-CNF and L-CNF have a pure cellulose core and the associated benefits of strength, low density, etc., the intentionally engineered lignin-coating provides a 
compatible surface for incorporation into plastics and other high-volume, non-aqueous end-use applications. Lignin is nature's second most abundant polymer after cellulose and is relatively hydrophobic and non-polar in nature. It is an underutilized, low value byproduct of biomass biorefineries such as AVAP and an ideal, low cost solution for hydrophobic surface modification of CNs.

Currently, most regulatory bodies address NM regulatory reviews on a case-by-case basis (e.g. the U.S. Environmental Protection Agency and the U.S. Food and Drug Administration (FDA 2014). Each organization has differing requirements for safety demonstration due to governing regulatory statutes. Policies and guidance directly addressing nanoscale materials are actively being developed by regulatory authorities globally. There is currently no widely agreed approach for how to appropriately test materials to ensure safety. A proactive approach to the development of data and demonstration of safety addressing occupational, consumer and environmental exposures was developed. Based on current guidance, we describe a testing strategy relevant for industry, that characterizes and demonstrates the safety of these novel cellulosic materials prior to full-scale commercialization.

\section{Materials and Methods}

\subsection{Development of the testing plan}

Prior to testing, a well-reasoned testing plan must be developed. The selection of the toxicity tests performed here were based on: 1) the availability of existing toxicity data for similar materials, 2) the potential for different potency of effects, 3) a nano life cycle risk assessment (nanoLCRA) and, 4) guidance from government and international organizations. Previous work mined the literature to determine the types of data that exist and highlighted the major data gaps (Shatkin et al. 2016). A published nano-life cycle risk assessment was used to help identify areas of priority (see Shatkin \& Kim 2015) important to risk assessments of nanoscale materials. The test plan was organized on the basis of priority by Shatkin and Kim's study (2015) that ranked potential exposure scenarios throughout the life cycle of CNs based on a variety of uses and application categories. The plan was developed around available guidelines for nanomaterial testing, such as the general recommendations from the U.S. Environmental Protection Agency's "Reviewing New Chemicals under the Toxic Substances Control Act (TSCA)". This was supplemented by the "Recommended Toxicological Testing for Additives Used in Food" to help determine which tests would be appropriate for demonstrating the safe use of CNs in food (based on Low Concern, Level I testing) (FDA 2006). Additionally, the Registration, Evaluation, Authorization and Restriction of Chemical's (REACH's) minimum information requirements for standard registration of 1-10 tonnes of chemicals was also used as guidance (ECHA 2016). Where possible, our testing strategy used standard test guidelines and prioritized alternative tests (non-animal tests) over in vivo tests. The exposure scenarios include environmental impacts of the receiving waters at end-of-life disposal (e.g. to aquatic wildlife and through biodegradation), the ingestion of CN particles by consumers' accidental ingestion, and the potential for dermal contact during manufacturing and consumer application. Since studies with other types of materials also suggest that nanomaterials may be more explosive than their larger counterparts (Wu 2010; Wu et al. 2009), explosibility characteristics were prioritized as a potential unique effect for L-CNC, the smaller of the two materials investigated herein. Occupational inhalation exposure associated with the handling of dry BioPlus CN powders was investigated in a separate study performed by the National Institute for Occupational Safety and Health's (NIOSH) Nanotechnology Research Field Team. Furthermore, where data were available, 
testing was limited and bridging or read across of existing data was used rather than performing redundant testing.

Exposure concentrations and doses were chosen based on the recommendations given by the guidance documents, where possible. For example, the US EPA Method OPPTS 870.110 Up and Down Procedure in rats suggests that the test start at an upper limit of $5000 \mathrm{mg} / \mathrm{L}$. This test is designed to minimize the use of animals; if three animals survive this upper limit, then the test is terminated and no further doses are tested. The skin and eye irritation tests allowed for the application of the gel directly (7\% L-CNC and 3\% L-CNF), but the other tests were performed in aqueous solutions, and therefore the gel could not be used at full concentration, as it would be too viscous. For the aquatic risk assessments, a minimum of $100 \mathrm{mg} / \mathrm{L}$ was used for dosing; this value was chosen based on the Sustainable Futures/P2 Framework Manual (EPA 2012) New Chemical Program, that defines a substance as "low concern" as $>100 \mathrm{mg} / \mathrm{L}$ for acute toxicity tests. However, in most cases, we tested to even higher concentrations, to determine the limits where adverse effects may be observed.

A summary of the developed testing plan is provided in Table 1.

Table 1. Testing plan to characterize safety of L-CNC and L-CNF materials.

\begin{tabular}{|c|c|}
\hline Endpoint & Protocol \\
\hline \multicolumn{2}{|l|}{ 1. Physicochemical characterization } \\
\hline Particle size distribution, shape and aspect & Transmission electron microscopy \\
\hline ratio & Scanning electron microscopy \\
\hline \multirow{2}{*}{ Composition } & Infrared spectroscopy \\
\hline & Inductively coupled plasma optical emission spectroscopy \\
\hline Crystal structure & X-ray powder diffraction \\
\hline \multirow[t]{3}{*}{ Explosibility } & Explosion severity test (ASTM E1226) \\
\hline & Minimum explosible concentration test ASTM E1515) \\
\hline & Minimum ignition energy test (ASTM E2019) \\
\hline \multirow[t]{2}{*}{ Biodegradability } & Aerobic biodegradation (OPPTS 835.3140) \\
\hline & Anaerobic biodegradation (OECD 311) \\
\hline \multicolumn{2}{|l|}{ 2. Human health effects testing } \\
\hline Acute oral toxicity & Up and down procedure in rats (OPPTS 870.1100) \\
\hline Skin irritation & MatTek Epiderm skin irritation test (OECD 439) \\
\hline \multirow[t]{2}{*}{ Eye irritation } & Hen's egg test chorioallantoic membrane test \\
\hline & Bovine corneal opacity and permeability test (OECD 437) \\
\hline \multicolumn{2}{|l|}{ 3. Environmental effects testing } \\
\hline Microbial bioassay & Kinetic luminescent bacteria test (ISO 11348-3) \\
\hline Algal bioassay & Freshwater alga growth inhibition test (OECD 201) \\
\hline Aquatic invertebrate bioassay & Daphnia sp. acute immobilization test (OECD 202) \\
\hline Aquatic vertebrate bioassay & Acute toxicity to embryonic zebrafish \\
\hline
\end{tabular}

\subsection{Physico-chemical characterization of L-CNC and L-CNF for selected properties} Characterization was performed on the aqueous dispersion of the materials, unless otherwise stated. 


\subsubsection{Transmission electron microscopy}

Transmission electron microscopy (TEM) was used to image L-CNC. A 400mesh TEM grid with formvar and carbon film was glow discharged prior to use. The grid was floated on a droplet of dilute L-CNC $(0.1 \%$ wt.) for $\sim 2$ minutes (min) prior to rinsing with uranyl acetate stain ( $2 \% \mathrm{wt}$. in water) and blotting dry. Samples were imaged using a Philips CM-100 TEM operated at 100kv, spot $3,200 \mu \mathrm{m}$ condenser aperture and $70 \mu \mathrm{m}$ objective aperture.

\subsubsection{Scanning electron microscopy}

Scanning electron microscopy (SEM) was used to image L-CNF. Conductive glass was applied to an aluminum stage using $5 \mathrm{~mm}$ carbon tape. Dilute L-CNF ( $<0.5 \%$ wt.) was dropped on the glass and the stage was placed in a vacuum oven at low temperature to dry. The dried sample was coated with gold sputtering for $1 \mathrm{~min}$ with a thickness on the order of 1-2nm. Samples were imaged using a LEO 1530 thermally-assisted field emission (TFE) scanning electron microscope.

\subsubsection{Surface charge}

The zeta potential of L-CNC and L-CNF in water were measured using a Malvern Zetasizer Nano ZS 90. In addition, zeta potential was measured in fishwater, the zebrafish exposure media $(0.26 \mathrm{~g} / \mathrm{L}$ Instant Ocean salts in reverse osmosis water with $\mathrm{pH}$ adjusted to $7.2 \pm 0.2$ using $\sim 0.1 \mathrm{~g}$ sodium bicarbonate, conductivity $480-600 \mu \mathrm{S} / \mathrm{cm}$ ) at $50 \mathrm{mg} / \mathrm{L}$. Samples were measured with and without dissolved organic matter (DOM), and with and without ultrasonication (10 minutes using a Sonics VCX-750 equipped with a cup-horn style probe).

\subsubsection{Infrared spectroscopy}

Lignin or cellulose $(\sim 2.5 \mathrm{mg})$ was individually milled with $\mathrm{KBr}(0.5 \mathrm{~g})$ in a mortar and pressed into FT-IR pellets. Fourier Transformed Infrared (FT-IR) spectra of these samples were collected on a Nicolet Magna-IR ${ }^{\mathrm{TM}} 550$ spectrometer in the $4000-400 \mathrm{~cm}^{-1}$ region with a spectral resolution of 4 $\mathrm{cm}^{-1}$ using 64 scans per spectrum in the absorption mode. The organosolv lignin control (from hardwood Populus trichocarpa) was obtained from Oak Ridge National Laboratory. BioPlus Lignin 1 was isolated from softwood chips and BioPlus Lignin 2 was isolated from hardwood chips using the AVAP process. The $\alpha$-cellulose control was obtained from Sigma (No. C-8002). The CNC-core and CNF-core were obtained by bleaching L-CNC and L-CNF to remove lignin.

\subsubsection{X-ray powder diffraction}

$\mathrm{X}$-ray powder diffraction (XRD) was used to determine the crystallinity of the CNC and CNF cores using a Rigaku Ultima IV X-ray Diffractometer $(40 \mathrm{kV}, 44 \mathrm{~mA})$ with a 2-Theta Range of $10^{\circ}-50^{\circ}$ and a scan speed of $0.2 \mathrm{deg} / \mathrm{min}$. The sample was run on a zero background holder, which are single silicon crystals cut at such an orientation as to produce minimal to no background. The pattern was analyzed with Jade 9 software using the crystalline peaks of cellulose at $14.6^{\circ}, 16.3^{\circ}, 21.7^{\circ}$, and $22.5^{\circ}$ and the amorphous peak at $18.8^{\circ}$. Crystallinity was determined using both Ruland's and Segal's equations. The CNC-core and CNF-core were obtained by bleaching L-CNC and L-CNF to remove lignin.

\subsubsection{Inductively Coupled Plasma Optical Emission Spectroscopy}

Inductively coupled plasma optical emission spectroscopy (ICP-OES) was performed to determine the composition of L-CNC and L-CNF. All samples were digested with $10 \mathrm{ml}$ of 70\% nitric acid in quartz tubes placed in a CEM SP-D 80 microwave system at $200^{\circ} \mathrm{C}$ for 3 min using a 5 min ramp. Samples were then transferred to $50 \mathrm{ml}$ volumetrics and brought to volume with $18 \mathrm{M} \Omega$ $\mathrm{H}_{2} \mathrm{O}$. A Horiba ULTIMA II high resolution spectrometer was used for the ICP-OES analysis. A 
concentric glass nebulizer and cyclonic spray chamber were used on the sample introduction system. Acquisition was done using 3 replicates in max mode and $1 \mathrm{sec}$ integration time per analyte. A $20 \mu \mathrm{m} / 15 \mu \mathrm{m}$ slit combination was used for all lines. Calibration was done using external standards with correlation coefficient $r>0.999$ for lines S180.676, Na589.592 and Ca393.366.

\subsubsection{Dust explosibility testing}

Powdered L-CNC was tested for explosibility. Metallic powders of nanomaterials have been shown found to be present a greater explosion hazard than conventional materials due to their higher surface area to volume ratio (Wu 2010; Wu et al. 2009; Dufaud et al. 2011). Since L-CNC has a higher surface area to volume ratio than L-CNF, it was used as a representative material to determine whether CNs represent an increased explosion hazard.

Prior to tests, L-CNC was tested for moisture content using a Mettler Toledo HR83 Halogen Moisture Analyzer to ensure that the powder was below the recommended range for moisture $(<5 \%$ as suggested by ASTM). In addition, $95 \%$ of the test materials must be below $75 \mu \mathrm{m}$; L-CNC was tested using a Cilas 1064 Particle Analyzer using a 200-mesh $(75 \mu \mathrm{m})$.

\subsubsection{Explosion severity test (EST)}

For EST, the ASTM standard E1226 "Standard Test Method for Explosibility of Dust Clouds" was performed. The EST measures the deflagration parameters of a combustible dust-air mixture, where maximum pressure $\left(\mathrm{P}_{\max }\right)$, the average maximum value for the rate of pressure increase per unit time $(\mathrm{dP} / \mathrm{dt})_{\max }$, and the deflagration index $\left(\mathrm{K}_{\mathrm{st}}\right)$ are measured.

Briefly, following standard test guidelines, a 20 liter (L) Siwek Chamber, equipped with an air nozzle to disperse the L-CNC dust, and two electrodes for connecting two squib (Sobbe) igniters (5 $\mathrm{kJ}$ each, $10 \mathrm{~kJ}$ total of ignition energy) to a voltage source. Two pressure transducers measured the pressure output of the explosion. The pressure-time data was collected by a high speed data acquisition system. An initial concentration of $125 \mathrm{~g} / \mathrm{m}^{3}$ was tested, then the dust concentration was systematically doubled until curves were obtained for both (dP/dt)max and Pmax that indicated an optimum value had been reached. At least two additional test series were run at the concentrations where the maximums were found and at one concentration on either side of the maximum.

\subsubsection{Minimum explosible concentration test (MEC)}

For MEC, the ASTM E1515 "Standard Test Method for Minimum Explosible Concentration of Combustible Dusts" was performed. MEC measures the minimum concentration of a combustible dust that can propagate a deflagration reaction in the air, under specified conditions of the test. This test provides the relative measure of a uniform dust cloud concentration that will allow an explosion.

The same $20 \mathrm{~L}$ Siwek Chamber set-up was used as in 3.2.6.1. Explosion Severity Test, except that only one squib igniter ( $5 \mathrm{~kJ}$ total) was used. Briefly, following standard test guidelines, the MEC was measured using successive tests at decreasing dust concentrations of L-CNC while using the $5 \mathrm{~kJ}$ strength ignition source. An explosion was differentiated from a non-explosion by evaluating the increase in pressure due to air-dust mixture explosion above that of the igniter alone. An explosion was defined as peak pressure that was at least one bar more than the igniter pressure. The rate of pressure rise $(\mathrm{dP} / \mathrm{dt})$ is not considered for MEC calculations. An initial concentration of 100 $\mathrm{g} / \mathrm{m}^{3}$ was tested. The dust concentration was then incrementally decreased by $10 \mathrm{~g} / \mathrm{m}^{3}$ until "explosion" and "non-explosion" were established. The MEC is interpolated between the "explosion" 
and "non-explosion" concentrations.

\subsubsection{Minimum ignition energy test (MIE)}

For MIE, the ASTM E2109 "Standard Test Method for Minimum Ignition Energy of a Dust Cloud in Air", with and without inductance, was performed. The test determines the relative ignition sensitivity of a dust cloud.

Briefly, following standard test guidelines, a Mike 3 MIE test apparatus (Kühner A.G., Switzerland) was used, equipped with a dust dispersion cup with a dispersion nozzle, a compressed air source (7 bar), and a pair of electrodes mounted on the clear glass cylinder wall (one a fixed high voltage electrode, the other a moving ground electrode). The discharge circuit consists of a high voltage supply $(15 \mathrm{kV}$ or $11 \mathrm{kV})$, interchangeable capacitors, and inductance source.

For each test, L-CNC (300-1500 mg) was placed in the cup around the dispersion nozzle. The electrode gap was set at $6 \mathrm{~mm}$. L-CNC was then dispersed as a dust cloud inside the chamber. After a delay, a computer controlled spark would discharge and observations would be made for flame ignition/propagation. An ignition, "Go" was defined when there was the appearance of a fireball in the chamber and is in contrast to a non-ignition, or "No Go". Once "Go/No Go" spark energy was found for a particular concentration, the procedure was repeated for higher and lower L-CNC concentrations. The spark energy was reduced in steps at the given L-CNC concentration until the dust cloud no longer ignited in ten repeated tests at a given energy. The procedure was repeated at different concentrations, and ignition delay times, until the lowest minimum ignition energy value was found. The MIE is reported as the energy between the highest energy that was not able to ignite the L-CNC dust cloud and the lowest energy that was able to ignite the dust cloud.

\subsubsection{Biodegradation}

\subsubsection{Aerobic biodegradation}

Aerobic biodegradation tests measure whether a material is biodegradable in aerobic environments. The test was performed according to the EPA's OCSPP 835.3140, "Ready Biodegradability $-\mathrm{CO}_{2}$ in Sealed Vessels (Headspace Test): Method B" using Good Laboratory Practice (GLP). This test uses a mixture of organic carbon inoculated with a mixed population of microorganisms from sewage treatment effluent that biodegrade the test substance. To gauge biodegradability, the amount of inorganic carbon produced in the test solutions are measured and reported in comparison to blanks. A reference sample of 1-octanol confirmed the validity of the results.

Briefly, aerobic mud was collected from the mixed treatment plant of urban $(\sim 66 \%)$ and industrial $(\sim 34 \%)$ liquid sewage in San Rocco, Italy. All medium were prepared according to the standard guidelines. Muds were mixed and allowed to settle for up to seven days then centrifuged, washed, and analyzed to quantify suspended solids concentration for the inoculum preparation prior to testing. The mud consisted of $21.17 \mathrm{mg} / \mathrm{L}$ of organic carbon for L-CNC, and $20.08 \mathrm{mg} / \mathrm{L}$ for L-CNF. The L-CNC and L-CNF were first ultra-sonicated, then $100 \mathrm{~g}$ of test sample $(2.9 \mathrm{~g}$ total of L-CNC, $2.5 \mathrm{~g}$ total of L-CNF) were added to $2000 \mathrm{~mL}$ of culture medium. The sample was incubated with the mud, under continual stirring in the darkness at $25 \pm 2^{\circ} \mathrm{C}$ for 28 days. At least 12 hours before samples were analyzed for total inorganic carbon (TIC), $6 \mathrm{~mL}$ of sodium hydroxide (1M) was added to stop the reaction. Samples were analyzed weekly for TIC using an automatic total organic carbon (TOC) analyzer. Biodegradation was expressed as the percentage ratio between the amount of 
inorganic carbon produced by the biodegradation of the test item and the amount of organic carbon of the test item added at the beginning.

\subsubsection{Anaerobic biodegradation}

Anaerobic biodegradation tests measure the whether a material is degradable in anaerobic environments. The test was performed according to OECD TG 311, "Anaerobic biodegradability of organic compounds in digested sludge: by measurement of gas production" using GLP. Tests were performed with a mixture of organic carbon, then a mixed population of microorganisms from sewage treatment effluent biodegrade the test substance and the amount of inorganic carbon produced in the test solutions are measured and reported in comparison to blanks to gauge biodegradation. A reference sample of sodium benzoate confirmed the validity of the results.

Briefly, aerobic mud was collected from the mixed treatment plant of urban $(\sim 66 \%)$ and industrial $(\sim 34 \%)$ liquid sewage in San Rocco, Italy. All medium were prepared according to the standard guidelines. Muds were mixed and allowed to settle for up to seven days in anaerobic conditions, then centrifuged, washed, and analyzed to quantify suspended solids concentration for the inoculum preparation prior to testing. Sludge was washed and centrifuged (3000 g for $5 \mathrm{~min}$ ) just prior to use to reduce the inorganic carbon concentration to less than $10 \mathrm{mg} / \mathrm{L}$. The pellet was then suspended in oxygen free test medium. The final concentration of total test solid was $1.55 \mathrm{~g} / \mathrm{L}$ for L-CNC, and $2.00 \mathrm{~g} / \mathrm{L}$ for L-CNF; $50.9 \mathrm{mg} / \mathrm{L}$ of TOC was used for L-CNC and $100.2 \mathrm{mg} / \mathrm{L}$ for L-CNF. The sample was incubated with the mud at $35 \pm 2^{\circ} \mathrm{C}$ for 60 days. The increased of pressure in each bottle was measured weekly using an automatic system of pressure reading. TIC was measured using an automatic SHIMADZU TOC analyser. Biodegradation was measured as the percentage ratio of the carbon in the headspace plus the inorganic carbon in solution, as compared to the initial organic carbon.

\subsection{Human health effects testing}

Germ cell mutagenicity was one of the only categories where adequate data exist for both CNCs and CNFs (Shatkin et al. 2016) that in combination with a lack of indication of genotoxicity for any cellulose rendered testing unnecessary in this testing plan.

\subsubsection{Acute oral toxicity}

To test the acute oral toxicity of the CNs, the EPA's OPPTS 870.1100 "Acute Oral Toxicity, Up and Down Procedure" (UPD) was performed. Briefly, three 180-189 g female albino Sprague-Dawley derived rats are used for each treatment; treatments consist of a single dose via oral gavage. According to the guidelines, an initial limit dose of $5000 \mathrm{mg} / \mathrm{kg}$ was administered (between 0.91$0.98 \mathrm{~mL}$ ) and if the animal survives, the test is concluded. If the animal dies, lower concentrations are subsequently tested. Observations on mortality, signs of gross toxicity (evaluation of skin and fur, eyes and mucous membranes, respiratory, circulatory, autonomic and central nervous systems, somatomotor activity), and behavioral changes are made for 30 minutes post-dosing, during several hours post-dosing, and then once daily for 14 days. Body weight was monitored on days 7 and 14 . Gross necropsies were performed after the observation period and tissues and organs of the thoracic and abdominal cavities were examined. The standard test was performed under GLP conditions.

\subsubsection{Skin irritation}

To determine the potential dermal irritation of the CNs, a standardized in vitro test was performed: OECD 439 “in vitro Skin Irritation: Reconstructed Human Epidermis Test Method". The study was based on MatTek's protocol of in vitro EpiDerm ${ }^{\mathrm{TM}}$ Skin Irritation Test. Briefly, tissue samples were 
exposed to $70 \mathrm{~g} / \mathrm{L} \mathrm{L-CNC}, 30 \mathrm{~g} / \mathrm{L} \mathrm{L-CNF}$, negative control (phosphate-buffered saline), or positive controls (5\% sodium dodecyl sulfate) for 60 minutes. Following the exposure, tissue viability was measured using methyl thiazole tetrazolium (MTT) uptake and reduction. MTT absorbance was measured at $540 \mathrm{~nm}$ and the values were compared to the control exposure. According to the United Nations Globally Harmonized System of Classification and Labeling of Chemicals (GHS), materials that reduce tissue viability to $\leq 50 \%$ are classified as an irritant and if tissue viability is $>50 \%$ then the material is classified as a non-irritant. Any potential interference of the nanomaterials with the MTT dye were avoided (Ong et al. 2014) through multiple rinse steps; tissues were rinsed with phosphate buffered saline (PBS) after dosing and incubation, change of medium after $24 \mathrm{~h}$, and at the end of the incubation period. The test was performed under GLP.

\subsubsection{Eye irritation}

To avoid in vivo testing, two tests were employed to determine the potential for eye irritation as an alternative to the OECD's 405 Draize methodology.

\subsubsection{Bovine corneal opacity and permeability (BCOP)}

The standardized OECD 437 Bovine corneal opacity and permeability test (BCOP) was used to determine the potential for ocular irritation. In situ bovine corneas are dosed with $0.75 \mathrm{~mL}$ of test media for ten minutes, then opacity measurements and sodium fluorescein permeability were determined. Briefly, bovine eyes are stored in Hanks' Balanced Salt Solution (HBSS) and then defect-free corneas are dissected with a 2-3 $\mathrm{mm}$ rim of sclera left attached. Corneas are mounted in specially designed holders which separate the anterior and exterior chambers. The chambers are filled with minimal essential medium (MEM) and corneas are allowed to equilibrate at $32 \pm 1^{\circ} \mathrm{C}$ for 1-2 hours. Then, corneas were dosed according to the closed-chamber method; MEM was removed from the anterior chamber and $0.75 \mathrm{~mL}$ of test solution $(70 \mathrm{~g} / \mathrm{L} \mathrm{L-CNC}$ or $30 \mathrm{~g} / \mathrm{L} \mathrm{L-CNF})$ was added and holders were placed with anterior side up for $10 \pm 1$ minutes. Solution was then removed and corneas washed and filled with MEM. Opacity measurements were immediately performed. After 2 hours, another opacity measurement was made, and $1 \mathrm{~mL}$ of $0.4 \%$ fluorescein solution was added. After $90 \pm 5 \mathrm{~min}$, any dye that had passed through the cornea was measured (optical density at 490 $\mathrm{nm}$ ). Nanomaterials were not expected to interfere with the dyes as corneas were rinsed and new media added prior to using dye. In vitro irritancy score (IVIS) was calculated according to OECD 437 (the corrected mean opacity score + fifteen times the corrected mean optical density score). Exposure to only MEM was used as negative control, and $100 \%$ ethanol were used as a positive control. The BCOP tests were performed under GLP.

\subsubsection{Hen's egg test chorioallantoic membrane (HET-CAM)}

The HET-CAM Test for Non-Opaque Material was based on INVITTOX Protocol No. 47 HETCAM test, which exposes the chorioallantoic membrane of embryonated chicken eggs to a test substance for 10 days to look for potential damage. Briefly, fertile White Leghorn eggs are incubated at $37 \pm 1^{\circ} \mathrm{C}$ for 10 days and are rotated daily. On day 10 of development, viable eggs are chosen and a rectangular window removed (using a rotating Dremel ${ }^{\circledR}$ from the shell directly over the air sac. Eggs were dosed with $300 \mu \mathrm{L}$ of $7 \mathrm{~g} / \mathrm{L} \mathrm{L-CNC}$ or $3 \mathrm{~g} / \mathrm{L} \mathrm{L-CNF}$ within $30 \mathrm{~min}$ of opening, and observations on lysis, hemorrhage, and/or coagulation are made for the five min immediately following dosing, as well as severity (none, slight, moderate, or severe reaction) at 1 and 5 minutes post-dose. The irritation score (IS) is calculated based on the lysis, hemorrhage, and coagulation, and the threshold concentration (TH) is determined, which are used to classify the irritation 
potential. Six eggs were dosed for each material, including a vehicle control ( $0.9 \%$ saline) and a positive control $(0.1 \mathrm{~N}$ sodium hydroxide and also $1 \%$ sodium dodecyl sulfate).

\subsection{Environmental effects testing}

\subsubsection{Microbial bioassay}

An acute microbial toxicity test with the luminescent marine bacteria Vibrio fisheri was performed according to ISO 11348:3, "Water Quality - Determination of the Inhibitory Effect of Water Samples on the Light Emission of Vibrio fisheri (Luminescent Bacteria Test)". Briefly, this assay looks at the toxicity of $100 \mathrm{mg} / \mathrm{L}$ of L-CNC or L-CNF to V. fisheri (NRRL B-11177) over 5, 15, and $30 \mathrm{~min}$ based on luminescence intensity. The positive control consisted of $3.4 \mathrm{mg} / \mathrm{L}$ of 3,5 dichlorophenol.

\subsubsection{Algal bioassay}

A freshwater algal bioassay was performed according to OECD 201, "Freshwater Alga and Cyanobacteria, Growth Inhibition Test”. Briefly, the algae Pseudokirchneriella subcapitata were seeded at 11600 cells/mL for L-CNC exposures and 13300 cells/mL for L-CNF exposures at light intensity $4440-8880 \mathrm{lux} \pm 15 \%, 23 \pm 1^{\circ} \mathrm{C}$. P. subcapitata were exposed to $175,350,700,1400$, and $2800 \mathrm{mg} / \mathrm{L} \mathrm{L-CNC}$ and 75, 150, 300, 600, and $1200 \mathrm{mg} / \mathrm{L} \mathrm{L-CNF}$ in EPA Algae Growth Media (OECD 201) for 72 hours and growth inhibition was measured using a microscope with a counting chamber. Tests were repeated three times for each concentration and six times for control.

\subsubsection{Aquatic invertebrate bioassay}

The acute effect of L-CNC and L-CNF on invertebrates were tested according to OECD 202, "Daphnia sp., Acute Immobilisation Test". Initial range finding tests determined that test concentrations of $0.7,2.1,3.5,7$, and $14 \mathrm{~g} / \mathrm{L} \mathrm{L-CNC}$ and $0.3,0.9,1.5,3$, and $6 \mathrm{~g} / \mathrm{L}$ of L-CNF could be used in the experiment $(1,3,5,10$, and $20 \%$ of the original stock test substance). Briefly, test solutions were made in reconstituted hard synthetic freshwater and daphnids were exposed for $48 \mathrm{~h}$ in a static non-renewal system. At 24 and $48 \mathrm{~h}$ post exposure, daphnids were checked; any animals that were immobile (as measured through no response or movement within 15 seconds of test vessel agitation) were considered dead. The $48 \mathrm{~h}$ EC50 was calculated using CETIS statistical software.

\subsubsection{Aquatic vertebrate bioassay}

The acute toxicity of L-CNC and L-CNF to embryonic zebrafish was tested over a 5-day developmental assay. Fishwater (FW) exposure media was prepared by dissolving $0.26 \mathrm{~g} / \mathrm{L}$ Instant Ocean salts (Aquatic Ecosystems, Apopka, FL) in reverse osmosis water with pH adjusted to $7.2 \pm$ 0.2 using $\sim 0.1 \mathrm{~g}$ sodium bicarbonate, conductivity $480-600 \mu \mathrm{S} / \mathrm{cm}$. CNs were diluted in artificial FW to achieve samples with $2000 \mathrm{mg}$ solids/L. Solutions were made with and without $10 \mathrm{mg} / \mathrm{L}$ dissolved organic matter (DOM; Suwanee River Dissolved Organic Matter, stock concentration of $363 \mathrm{mg}$ DOM/L). Following dilution and addition of DOM to the replicate stock solutions, samples were ultra-sonicated for 10 minutes in a bath sonicator then diluted with $\mathrm{FW}$ to the final exposure concentrations $(0,0.2,10,20,100,250,500,1000,2000 \mathrm{mg} / \mathrm{L})$.

Zebrafish embryos were collected from group spawns of wild-type 5D fish maintained at the Sinnhuber Aquatic Research Laboratory at Oregon State University. Chorions were removed from embryos ('dechorionated') at 6 hours post fertilization (hpf) with protease in fish water (FW) following the methodology outlined in (Truong et al. 2011). A replicate set of exposures was also 
conducted with the chorion intact to determine if there was an impact on embryo hatching success. At $8 \mathrm{hpf}$, embryos were exposed individually to $150 \mu \mathrm{L} /$ well of test solution in clear 96 -well plates $(\mathrm{n}=24$ embryos per concentration for each material). Negative controls were exposed to FW and FW+DOM. All exposures were kept at $26.5^{\circ} \mathrm{C}$ under a $14: 10 \mathrm{~h}$ light:dark photoperiod. Parafilm was placed under the lid of each plate to prevent volatilization and evaporation. At $24 \mathrm{hpf}$ developing embryos were assessed for mortality, developmental progression, spontaneous movement, and notochord development. At $96 \mathrm{hpf}$ embryos were assessed for mortality and at $120 \mathrm{hpf}$ mortality was again assessed in addition to multiple sub-lethal developmental and behavioral responses including the presence of pericardial or yolk sac edema, abnormal development of the eye, snout, jaw, otic vesicle, heart, brain, somites, pectoral and caudal fins, pigmentation, circulation, body axis, trunk, swim bladder, and the development of touch response.

\section{Results and Discussion}

\subsection{Testing plan}

Previous efforts had identified a wealth of safety data are available for conventional (non-nano) cellulose materials, and some data exists for CNs without lignin-coating (see Figure 2 in Shatkin et al. 2016). While data on cellulose can be used as supporting data for CNs, the uncertainty that surrounds nanomaterials warrants a proactive approach to data collection and a full suite of testing was performed to fill the data gaps.

\subsection{Physico-chemical characterization of L-CNC and L-CNF for selected properties}

\subsubsection{Particle size distribution, shape, surface charge, and aspect ratio}

Scanning electron microcopy (SEM) and transmission electron microscopy (TEM) were used to determine the particle size distribution, shape and aspect ratio of L-CNC and L-CNF. Representative TEM (L-CNC) and SEM (L-CNF) images are shown in Figure 1. Since L-CNF particles are too large to characterize using TEM, SEM was used for their characterization. Particle size image analysis software was used to calculate the average dimensions of ten or more L-CNC particles from TEM images. L-CNC is rod-shaped with an average length of $317 \pm 60 \mathrm{~nm}$ and width of $14 \mathrm{~nm}$. The approximate dimensions of L-CNF particles were determined by manual measurement of ten or more particles from SEM images. L-CNF is fibrillar-shaped with lengths ranging from $500 \mathrm{~nm}$ to several microns and average widths of $14-200 \mathrm{~nm}$. The aspect ratio of L-CNC was calculated to be 23 by dividing the average particle length by the average particle width. The aspect ratio distribution of the more polydisperse L-CNF particles, 26-215, was calculated for the range of particle dimensions observed. In water, L-CNC had a charge of $-18 \mathrm{mV}$ and L-CNF had a charge of $-22 \mathrm{mV}$. In fishwater, L-CNC had a charge of $-17 \mathrm{mV}$ and L-CNF had a charge of $-10 \mathrm{mV}$. Sonication did not change the zeta potential measurements. 


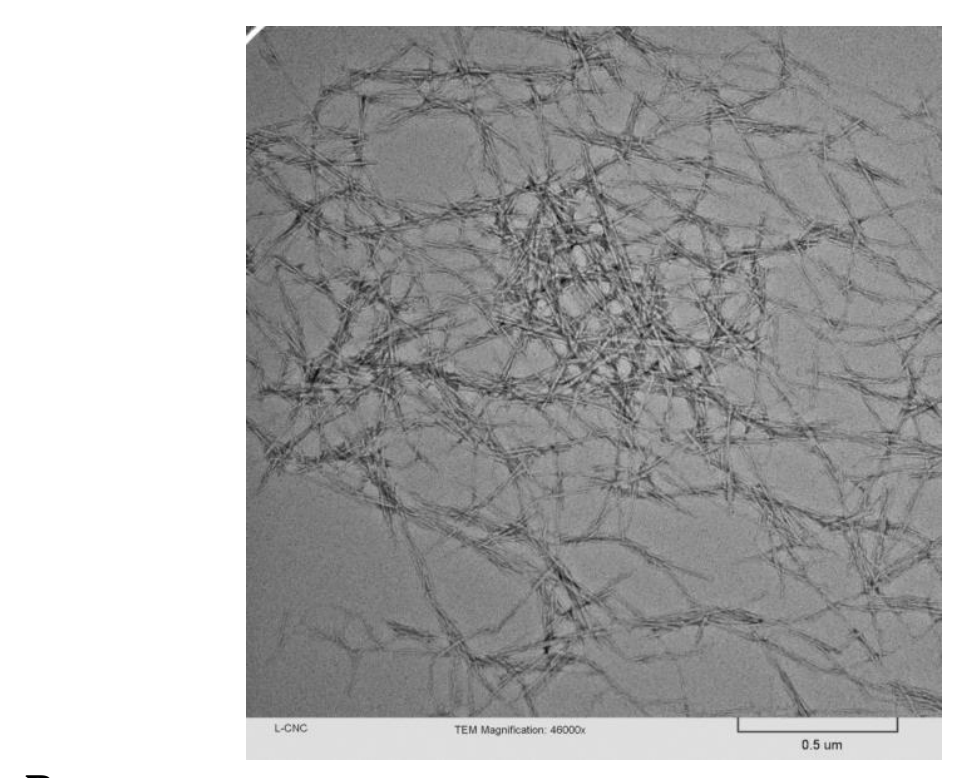

$\boldsymbol{B}$

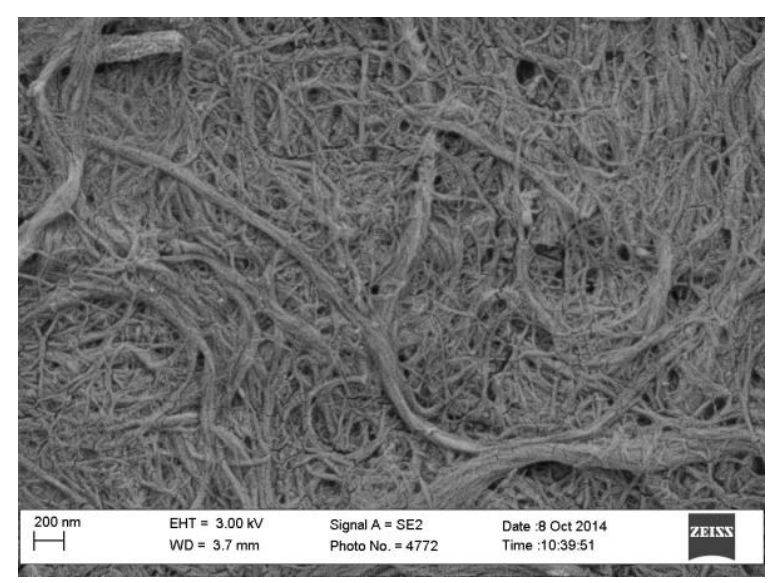

Figure 1. Representative TEM (A) and SEM (B) images of L-CNC (A) and L-CNF (B).

\subsubsection{Composition}

Infrared spectroscopy results for L-CNC and L-CNF are provided in in Supplemental Figure 1. According to the spectra, the cellulose core of the lignin-coated particles is equivalent to alphacellulose purchased from Sigma (CAS \# 9004-34-6) and the lignin coating is equivalent to Organosolv lignin (CAS \# 8068-03-9), which is known to preserve the original chemical structure of lignin as it exists in biomass.

The compositional results from inductively coupled plasma optical emission spectroscopy (ICPOES) are shown in in Supplemental Figure 2. L-CNC has a calcium, sodium and sulfur content of $0.02 \%, 0.02 \%$ and $0.05 \%$, respectively by weight, while L-CNF contains $0.05 \%, 0.05 \%$ and $0.09 \%$ calcium, sodium and sulfur content by weight.

\subsubsection{Crystal Structure}

X-ray powder diffraction revealed that the core of L-CNC has a crystallinity of $98 \%$ according to both the Ruland and Segal equations. L-CNF has a crystallinity of $97 \%$ according to the Ruland equation and $95 \%$ according to the Segal equation. The corresponding X-ray diffraction patterns are 
provided in in Supplemental Figure 3. Lignin is an amorphous polymer, therefore the lignin coated of both L-CNC and L-CNF is amorphous.

\subsubsection{Dust explosibility testing}

Spray-dried L-CNC powder was produced with a GEA Niro Spray Drier at a commercial spraydrying facility to a final moisture content of $3.6 \% \mathrm{wt}$. The moisture content and particle size distribution of the powders were within the acceptable range for explosibility testing $(<5 \%$ and $100 \%$ of particles less than $<75 \mu \mathrm{m}$, respectively). The mean particle size of the L-CNC powder was $18 \mu \mathrm{m}$. Spray-drying is a common method for obtaining dry powders of CNs where agglomerates of individual CNs are obtained with an agglomerate particle size typically in the range of 10-30 $\mu \mathrm{m}$, depending on the atomization configuration of the spray-drier used (Peng et al. 2012). While conventional, pure cellulose CNs are known to bond irreversibly during drying so that the individual nanoparticle morphology is lost, drying aides that prevent inter-particle bonding can be used (Agenda 2020 Technology Alliance, 2016). The lignin-coating on L-CNC and L-CNF has been shown to prevent irreversible bonding during drying, so that individual CN's remain within the dried powder agglomerate (Figure 2) (Gupta et al. 2017) As the agglomerate size is determined by the spray-drier configuration for both L-CNC or L-CNF, dust explosibility testing was performed only on L-CNC powder.

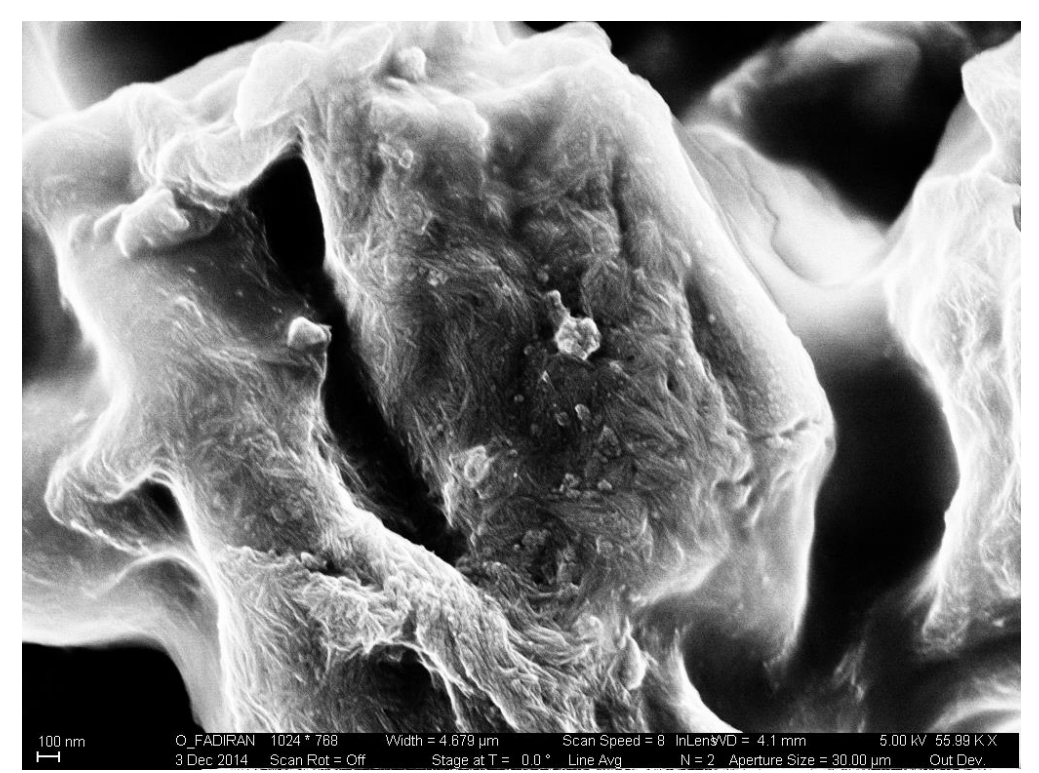

Figure 2. SEM of spray-dried agglomerate composed of individual L-CNC particles

Many dusts can be explosive (e.g. milk powder, charcoal, zinc). A flammability rating has not been assigned to a conventional cellulose dust by the National Fire Protection Association, but might be flammable under certain conditions (NIOSH 1995). Changes in surface chemistry and other pchem properties will likely affect the flammability of CNs (Fox et al. 2012; Fox et al. 2013).

Conventional cellulose dust is combustible at $240^{\circ} \mathrm{C}$ (Raemy \& Loeliger 1985) and is classified as "St 2 - Strong Explosion" based on a dust deflagration index $\left(\mathrm{K}_{\mathrm{st}}\right)$ of 229 (NFPA 2013; OSHA 2009). Interestingly, in the current study the L-CNC was determined to have a $\mathrm{K}_{\mathrm{st}}$ of 146, classifying it as a "St 1 - Weak to Moderately Explosible" class dust, which is lower than conventional cellulose dust. Other studies have reported that NM powders have greater explosion hazard than conventional materials, but most studies have been performed on metallic NMs (Wu 2010, Wu et al. 2009, 
Dufaud et al. 2011). This suggests that in occupational settings where these CNs are produced, there is a lower explosion hazard than in facilities where conventional cellulose is manufactured. The lowest concentration at which an ignition was observed was $60 \mathrm{~g} / \mathrm{m}^{3}$ (Eckhoff 2003), and no ignition was observed at $70 \mathrm{~g} / \mathrm{m}^{3}$. Therefore, the interpolated MEC of L-CNC was determined to be $66 \mathrm{~g} / \mathrm{m}^{3}$, which is similar to the reported value for cellulose $\left(60 \mathrm{~g} / \mathrm{m}^{3}\right)$.

The L-CNC had an MIE value that was between $10 \mathrm{~mJ}$ and $30 \mathrm{~mJ}$, with an interpolated value of 14 $\mathrm{mJ}$, when tested with inductance. Without inductance, the sample had an MIE value that was between $300 \mathrm{~mJ}$ and $1000 \mathrm{~mJ}$, with an interpolated value of $360 \mathrm{~mJ}$. It should be noted that these are relative data and are specific to the sample, method, and equipment used. It is interesting to note that $\mathrm{L}-\mathrm{CNC}(14 \mathrm{~mJ})$ has a lower MIE (with inductance) than cellulose $(35 \mathrm{~mJ})$.

\subsubsection{Biodegradation}

Biodegradation is an important characteristic that contributes to the environmental fate of materials. Biodegradable substances rapidly degrade in the environment and are unlikely to accumulate. Cellulose, the most abundant biopolymer on earth, is well documented to be biodegradable in both aerobic and anaerobic environments (Fernandes et al. 2011; Leshine 1995). For aerobic biodegradation, a material is considered "readily biodegradable" (i.e. the material will rapidly and completely biodegrade in aquatic environments under aerobic conditions), if the biodegradation of the material reaches $>60 \%$ within the 10 -day window after reaching $10 \%$ biodegradation. L-CNC reached $10 \%$ biodegradation between day 1 and 7 , was $41 \%$ by day 14 , and reached $68 \%$ by day 21 (Supplemental Figure 4), and as expected can be considered "biodegradable" under aerobic conditions. L-CNF reached $10 \%$ between day 1 and 7, and was $71 \%$ degraded by day 14 . Therefore, L-CNF is considered "readily biodegradable". These results are in agreement with published studies examining the aerobic biodegradability of CNCs. O'Connor et al., (2014) reported 42\% biodegradation of sulfated CNC within the 10-day window. Similarly, Kummerer et al., (2011) reported an aerobic biodegradation rate of $46 \%$ and $54 \%$ by days 14 and 28, respectively for CNC. The biodegradation was higher for CNC compared to conventional forms of cellulose which had degraded by $21 \%$ and $45 \%$ by days 14 and 28 , likely due to their size and higher surface area.

Anaerobic biodegradation is representative of the expected degradation rates in waste water treatment or anaerobic sludge digestion for composting. For L-CNC there was $3.54 \mathrm{mg}$ of total carbon at the end of the test, and $10.18 \mathrm{mg}$ initial organic carbon, resulting in $35 \%$ anaerobic biodegradation. For L-CNF there was $5.20 \mathrm{mg}$ of total carbon at the end of the test, and $10.18 \mathrm{mg}$ initial organic carbon, resulting in $51 \%$ anaerobic biodegradation. These values are similar or higher than those reported for conventional cellulose, where $35 \pm 5 \%$ of cellulose degraded after 62 days of solid-state anaerobic conditions (Motte et al. 2015).

\subsection{Human health effects testing}

Cellulose has a long history of safe use in the food, packaging, and forest products industry and along with several of its derivatives, are classified as "Generally Recognized as Safe" (GRAS) by the FDA. The range of human health effects testing including acute oral, dermal, and eye toxicity studies performed here revealed that there was no oral, dermal or ocular toxicity following L-CNC and L-CNF exposure (Table 2). Looking to guidance from the EPA, OECD, the European Union Reference Laboratory for Alternatives to Animal Testing (EURL ECVAM) and GHS, these substances would be classified as "practically non-toxic" and "not an irritant". Published studies of 
related cellulose materials support the data found here indicating a lack of toxicity observed for L$\mathrm{CNC}$ and L-CNF.

Table 2. Summary of toxicological testing completed for L-CNC and L-CNF.

\begin{tabular}{|c|c|c|c|}
\hline \multirow{2}{*}{$\begin{array}{c}\text { Mammalian } \\
\text { Health Endpoint }\end{array}$} & \multirow[t]{2}{*}{ Protocol } & \multicolumn{2}{|c|}{ Results } \\
\hline & & L-CNC Gel & L-CNF Gel \\
\hline Acute Oral Toxicity & $\begin{array}{l}\text { Up and Down } \\
\text { Procedure in Rats } \\
\text { (OPPTS 870.1100) }\end{array}$ & $\mathrm{LD}_{50}>5000 \mathrm{mg} / \mathrm{kg}$ & $\mathrm{LD}_{50}>5000 \mathrm{mg} / \mathrm{kg}$ \\
\hline \multirow[t]{2}{*}{ Skin Irritation ${ }^{1}$} & $\begin{array}{l}\text { MatTek EpiDerm } \\
\text { Skin Irritation Test } \\
\text { (OECD TG 439) }\end{array}$ & $\begin{array}{l}70,000 \mathrm{mg} / \mathrm{L} \mathrm{L}-\mathrm{CNC} \text { is a } \\
\text { non-irritant: } \\
\text { Mean tissue viability = } \\
97.3 \%\end{array}$ & $\begin{array}{l}30,000 \mathrm{mg} / \mathrm{L} \mathrm{L}-\mathrm{CNF} \text { is } \\
\text { a non-irritant: } \\
\text { Mean tissue viability = } \\
97.5 \%\end{array}$ \\
\hline & $\begin{array}{l}\text { Hen's Egg Test } \\
\text { Chorioallantoic } \\
\text { Membrane Test }\end{array}$ & $\begin{array}{l}7,000 \mathrm{mg} / \mathrm{L} \mathrm{L}-\mathrm{CNC} \text { has } \\
\text { none to slight irritation } \\
\text { potential; irritation } \\
\text { score of } 0 .\end{array}$ & $\begin{array}{l}3,000 \mathrm{mg} / \mathrm{L} \mathrm{L}-\mathrm{CNF} \text { has } \\
\text { none to slight } \\
\text { irritation potential; } \\
\text { irritation score of } 0 .\end{array}$ \\
\hline Eye Irritation ${ }^{1}$ & $\begin{array}{l}\text { Bovine Corneal } \\
\text { Opacity and } \\
\text { Permeability Test } \\
\text { (OECD TG 437) }\end{array}$ & $\begin{array}{l}70,000 \mathrm{mg} / \mathrm{L} \mathrm{L}-\mathrm{CNC} \text { is a } \\
\text { non-irritant; } \\
\text { in vitro irritancy score: } \\
0.73\end{array}$ & $\begin{array}{l}30,000 \mathrm{mg} / \mathrm{L} \mathrm{L}-\mathrm{CNF} \text { is } \\
\text { a non-irritant; } \\
\text { in vitro irritancy score: } \\
0.45\end{array}$ \\
\hline
\end{tabular}

${ }^{1}$ Results shown are for L-CNC and L-CNF material not gel product (L-CNC gel is 7\% L-CNC material, and $\mathrm{L}-\mathrm{CNF}$ gel is $3 \% \mathrm{~L}-\mathrm{CNF}$ material). $\mathrm{LD}_{50}=$ lethal dose that kills $50 \%$ of animals

\subsubsection{Acute oral toxicity}

No negative effects were observed in any animals. All animals survived the administration of 5000 $\mathrm{mg} / \mathrm{kg} \mathrm{L-CNC}$ and L-CNF, gained body weight, and appeared active and healthy during the study. There were no signs of gross toxicity, adverse clinical effects, or abnormal behavior. No gross abnormalities were noted for any of the animals when necropsied at the conclusion of the 14-day observation period. Based on this, L-CNC and L-CNF have an acute oral $\mathrm{LD}_{50}>5000 \mathrm{mg} / \mathrm{kg}$.

Similarly, studies looking at acute, sub-acute ( $<28$ days), sub-chronic ( $<90$ days), and chronic exposure to conventional cellulose show no reported toxicity, even when cellulose contributes to a relatively high percentage of the diet (Sundaravalli et al. 1971; Hove 1979). Rats orally gavaged daily with up to $5 \mathrm{~g} / \mathrm{kg}$ microcrystalline cellulose (MCC) did not accumulate MCC within their tissues, nor experience significant toxicological effects, including no differences in weight gain, food consumption, blood chemistry, or organ abnormalities (Kotkoskie et al. 1996). When added as a dietary food supplement, cellulose (4-50\% of diet) showed no major effects in rats (Paturi et al. 2010) or sheep (Oltjen et al. 1962). Similarly, there is no indication of oral toxicity resulting from acute, sub-acute or chronic exposure to CNC. Exposure to CNC produced via the sulfate process in rats showed no adverse effects at the highest dose examined (LD50 > $2000 \mathrm{mg} / \mathrm{kg}$ ) (O'Connor et al. 2014). Repeated-dose oral exposures to CNC for 28 days was evaluated in rodents; no mortality or adverse effects were noted from daily oral gavage at the highest dose examined (NOAEL $=2000$ $\mathrm{mg} / \mathrm{kg}$ ) (O'Connor et al. 2014). This is the first study that shows that acute exposure of rats to high 
doses $(5 \mathrm{~g} / \mathrm{kg})$ of a form of CNF has no gross effects, including morphological and behavioral changes.

\subsubsection{Skin irritation}

Exposure to L-CNC and L-CNF did not reduce the viability of the tissue. L-CNC resulted in a final $97.3 \%$ tissue viability and L-CNF in $97.5 \%$ tissue viability. Therefore, both are classified as a 'nonirritant' according to the GHS. Other studies show supporting results for both conventional celluloses and sulfated CNCs. Occlusive dermal exposure to conventional cellulose did not result in irritation in rabbits (WHO 1998). Similarly, sulfated CNC was not irritating and had no corrosive effects in rabbits (O'Connor 2014). Topical dermal exposures of cellulose or CNC (103 mg/mL) did not result in skin sensitization in Guinea pigs (WHO/FAO 1998; O'Connor 2014). Intradermal injection of CNC (1.1 mg/mL) did not cause sensitization (O'Connor et al. 2014).

\subsubsection{Eye irritation}

For the BCOP study, exposure to L-CNC resulted in an IVIS of 0.73 , based on a corrected mean opacity score of 0.67 , and a corrected mean optical density of 0.004 . Exposure to L-CNF resulted in an IVIS of 0.45 , based on a corrected mean opacity score of 0.34 , and a corrected mean optical density of 0.007 . According to the OECD 437, GHS, and EURL ECVAM Protocol 124, an IVIS score of $\leq 3$ classifies L-CNC and L-CNF as "no category", or a "non-eye irritant".

The HET-CAM tests showed that exposure to both L-CNC and L-CNF resulted in no hemorrhage, lysis, or coagulation, resulting in an irritation score of 0 (no irritation). The threshold concentration was $>7 \mathrm{~g} / \mathrm{L} \mathrm{L-CNC}$ and $>3 \mathrm{~g} / \mathrm{L}$ L-CNF. Due to this high threshold concentration and an irritation score of 0 , the irritation potential is classified as "none to slight". Similarly, a WHO report (1998) reported that MCC was judged to be minimally irritating after instillation into the eyes of rabbits, though the concentrations were not documented.

\subsection{Environmental effects testing}

Cellulose is an abundant and natural material and serves as a fuel source for many parts of the food web, therefore low toxicity is expected in the environment. Prior studies with sulfated CNC showed very low toxicity (Kovacs et al. 2010; Harper et al. 2016) but, since L-CNC and L-CNF have different surface chemistry because of the lignin-coating, we performed ecological testing to demonstrate their benign nature, even at artificially high concentrations under testing conditions that mimic realistic environmental conditions. Environmental toxicity testing examined the potential effects of L-CNC and L-CNF exposure to a variety of aquatic organisms including bacteria ( $V$. fisheri), algae (P. subcapitata), invertebrates (D. magna), and vertebrates (D. rerio). Little to no toxic effects were reported for either L-CNC or L-CNF in these tests (Table 3), even at artificially high concentrations that would not feasibly be released to the environment. Together, with published studies examining the effects of related substances, results demonstrate that L-CNC and L-CNF are environmentally benign with a low Concern Level according to the U.S. EPA Sustainable Future Summary Assessment.

Table 3. Summary of environmental toxicity testing for L-CNC and L-CNF.

\begin{tabular}{llccc} 
Endpoint & Protocol & Result & EPA New \\
L-CNC Gel & L-CNF Gel & $\begin{array}{c}\text { Chemical } \\
\text { Program SF }\end{array}$ \\
\hline
\end{tabular}




\begin{tabular}{|c|c|c|c|c|}
\hline & & & & Concern Level $^{2}$ \\
\hline $\begin{array}{l}\text { Microbial } \\
\text { Bioassay } \\
\text { (V. fischeri) }\end{array}$ & $\begin{array}{l}\text { Kinetic Luminescent } \\
\text { Bacteria Test (ISO } \\
\text { 11348-3) }\end{array}$ & EC50>100 mg/L & EC50>100 mg/L & \\
\hline $\begin{array}{l}\text { Algal Bioassay }^{1} \\
\text { (P. subcapitata) }\end{array}$ & $\begin{array}{l}\text { Freshwater Alga } \\
\text { Growth Inhibition } \\
\text { Test (OECD TG 201) }\end{array}$ & $\begin{array}{l}\text { EC50>2,800 mg/L } \\
\text { NOEC }=175 \mathrm{mg} / \mathrm{L}\end{array}$ & $\begin{array}{l}\text { EC50>1,200 } \\
\mathrm{mg} / \mathrm{L} \\
\mathrm{NOEC}=300 \mathrm{mg} / \mathrm{L}\end{array}$ & low concern \\
\hline $\begin{array}{l}\text { Acute Toxicity } \\
\text { to Invertebrates } \\
(\text { D. magna })^{1}\end{array}$ & $\begin{array}{l}\text { Daphnia sp. Acute } \\
\text { Immobilization Test } \\
\text { (OECD TG 202) }\end{array}$ & $\begin{array}{l}\text { EC50 11,000 mg/L } \\
\text { NOEL=7,000 mg/L }\end{array}$ & $\begin{array}{l}\text { EC50>6,000 } \\
\mathrm{mg} / \mathrm{L} \\
\mathrm{NOEL}=6,000 \\
\mathrm{mg} / \mathrm{L}\end{array}$ & low concern \\
\hline $\begin{array}{l}\text { Acute Toxicity } \\
\text { to Vertebrates; } \\
\text { Early Life Stage } \\
\text { (D. rerio) }\end{array}$ & $\begin{array}{l}\text { Acute Toxicity to } \\
\text { Embryonic } \\
\text { Zebrafish }\end{array}$ & LC50>2000 mg/L & $\mathrm{LC} 50>2000 \mathrm{mg} / \mathrm{L}$ & low concern \\
\hline
\end{tabular}

\subsubsection{Microbial bioassays}

Exposure to $100 \mathrm{mg} / \mathrm{L}$ caused no inhibition of luminescence in $V$. fisheri, thereby resulting in an Effects concentration for $50 \%$ of the Population (EC50) > $100 \mathrm{mg} / \mathrm{L}$ for both L-CNC and L-CNF. This is supported by other studies, which also found no significant effects of CNs, even at much higher concentrations. The Inhibitory concentration causing a 25\% decrease in luminescence (IC25) was $>10000 \mathrm{mg} / \mathrm{L}$ for sulfated CNC (Kovacs et al. 2010), and the No observable adverse effects level (NOAEL) for sulfated CNC and conventional cellulose was determined to be $>2500 \mathrm{mg} / \mathrm{L}$, and CNF inhibited light production by $23 \%$ after exposure to $2500 \mathrm{mg} / \mathrm{L}$ (Vartiainen et al. 2011).

\subsubsection{Algal bioassays}

For L-CNC, the no observed effect concentration (NOEC) on average growth rate of $P$. subcapitata was $175 \mathrm{mg} / \mathrm{L}$ and exposure to $350 \mathrm{mg} / \mathrm{L}$ resulted in a decrease in survival to $79 \pm 4 \%$ compared to control (Figure 3). For L-CNF, the NOEC on average growth rate was $300 \mathrm{mg} / \mathrm{L}$, and the $\mathrm{EC}_{50}$ was $>1.2 \mathrm{~g} / \mathrm{L}$. Other studies on $P$. subcapitata exposed to various forms of sulfated CNC report that the inhibitory concentration to $25 \%$ of the population $\left(\mathrm{IC}_{25}\right)$ is higher than $10 \mathrm{~g} / \mathrm{L}$, but it is difficult to directly compare the values to this study as no other values are reported and the NOEC is unknown (Kovacs et al. 2010). 
A

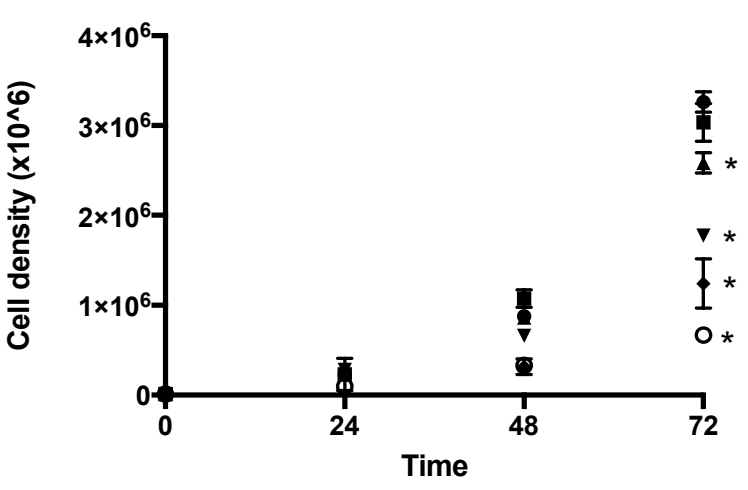

B

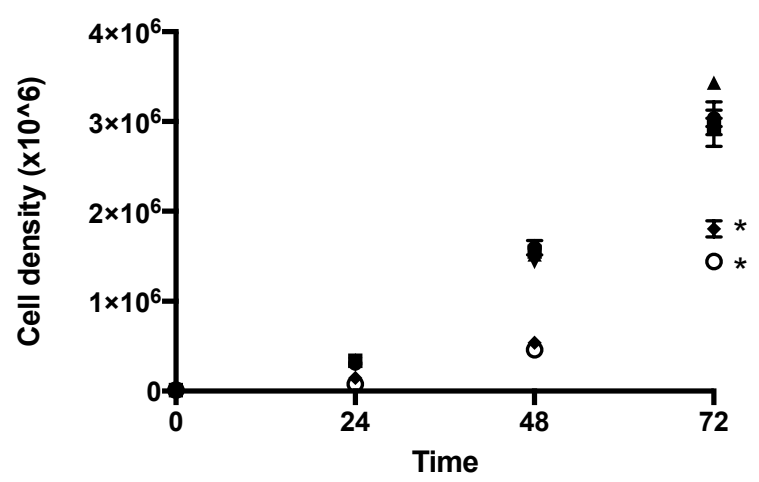

Figure 3 Algae bioassays. (A) P. subcapitata were exposed to $\square 0, \square 0.175, \boldsymbol{\Delta} 0.35, \boldsymbol{\nabla} 0.7, \square 1.4$, and $\square 2.8 \mathrm{~g} / \mathrm{L} \mathrm{L-}$ $\mathrm{CNC}$ and cell density measured at 24,48 , and $72 \mathrm{~h}$. (B) P. subcapitata were exposed to $\square 0, \square 0.075, \boldsymbol{\Delta} 0.15, \boldsymbol{\nabla} 0.30$, 0.6, and $1.2 \mathrm{~g} / \mathrm{L} \mathrm{L-CNF}$ and cell density measured at 24,48 , and $72 \mathrm{~h} . *$ represents significantly different cell density compared to $0 \mathrm{~g} / \mathrm{L}$ control ( $\mathrm{p}<0.05$; ANOVA, Tukey's multiple comparison test)

\subsubsection{Invertebrate bioassays}

Exposure to the highest concentration of L-CNC $(14 \mathrm{~g} / \mathrm{L})$ caused a reduction in survival in daphnia $(30 \pm 13 \%)$, whereas there was no reduction in survival when exposed to L-CNF at the highest concentration $(6 \mathrm{~g} / \mathrm{L})$ (Figure 4). Based on the results, the no observed adverse effects level (NOAEL) was $7 \mathrm{~g} / \mathrm{L}$ for $\mathrm{L}-\mathrm{CNC}$ and $6 \mathrm{~g} / \mathrm{L}$ for L-CNF. Other reports have also found that only high concentrations of NCs affect invertebrates. Kovacs et al., (2010) examined the effects of sulfatedCNC exposure on several invertebrate species including D. magna and C. dubia (water fleas), $T$. platyurus (fairy shrimp) and $H$. attenuata (a cnidarian). Several types of CNC materials were investigated, and acute $\mathrm{LC}_{50}$ ranged from $>1$ to $>5 \mathrm{~g} / \mathrm{L}$ for D. magna and C. dubia, $13.2 \mathrm{~g} / \mathrm{L}$ for $T$. platyurus, and $>6.8$ to $14.2 \mathrm{~g} / \mathrm{L}$ for $H$. attenuata. Effects of CNC exposure on reproduction were also examined in C. dubia; reported $\mathrm{IC}_{25}$ in reproduction after 7 days exposure ranged from 200 to $>2000$ $\mathrm{mg} / \mathrm{L}$ (Kovacs et al. 2010). The lack of toxicity seen at high concentrations would suggest that $\mathrm{CN}$ toxicity to invertebrates is very low.

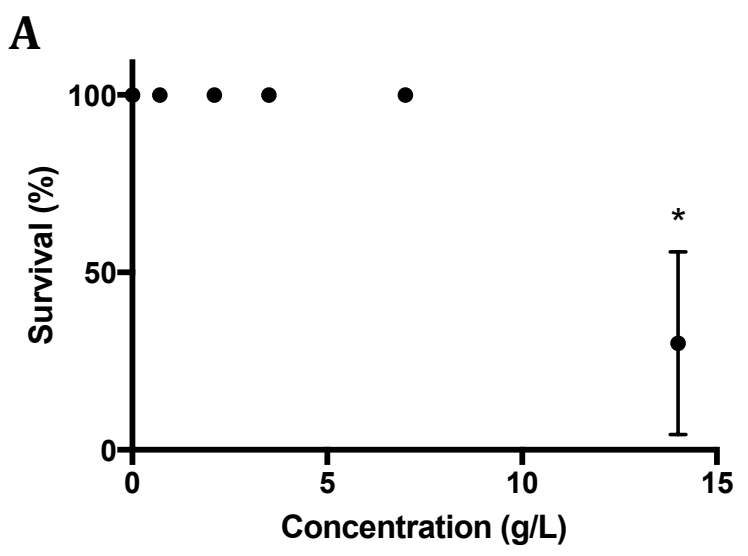

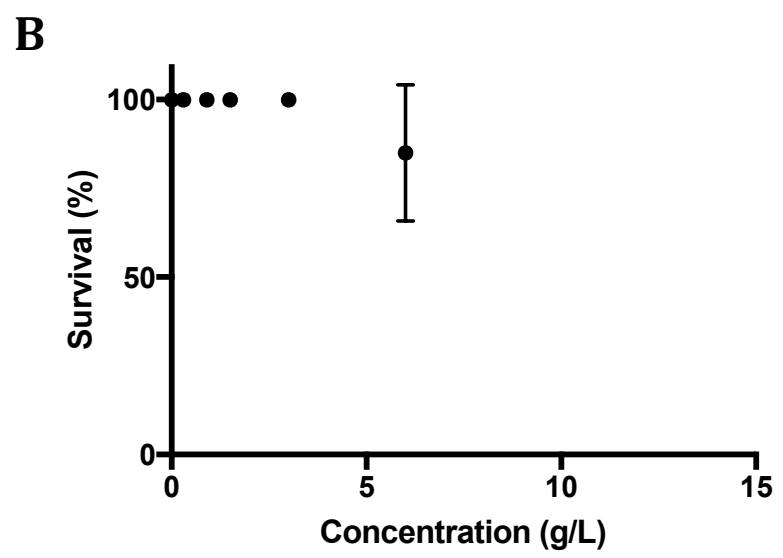

Figure 4. Invertebrate bioassays. D. magna were exposed to (A) 0.7, 2.1, 3.5, 7, and 14 g/L L-CNC and (B) 0.3, 0.9, $1.5,3$, and $6 \mathrm{~g} / \mathrm{L}$ of $\mathrm{L}-\mathrm{CNF}$ for $48 \mathrm{~h}$ in a static non-renewal system. Results show daphnid survival expressed as a 
percent. * represents significantly decreased survival in comparison to $0 \mathrm{~g} / \mathrm{L}$ control $(\mathrm{p}<0.05$; ANOVA, Tukey's multiple comparison test)

\subsubsection{Vertebrate bioassays}

Zebrafish with chorions left intact exposed to $2000 \mathrm{mg} / \mathrm{L} \mathrm{L-CNC}$ or L-CNF did not result in any significant mortality or sub-lethal effects from exposure, and hatching rate was unaffected by either material at any of the test concentrations (data not shown). Dechorionated zebrafish embryos exposed at 8 hours post fertilization (hpf) to L-CNC and L-CNF showed no significant signs of mortality or sub-lethal effects at any concentration at 24 or $96 \mathrm{hpf}$ (not shown). After exposure to the test solutions for 5 days ( $120 \mathrm{hpf}$ ), no significant mortality or sub-lethal effects (i.e. no significant pericardial edema or yolk sac edema) were observed for embryos exposed to the L-CNF samples (with or without dissolved organic matter (DOM) present). However, significant mortality was observed at the highest test concentration $(2000 \mathrm{mg} / \mathrm{L})$ for the L-CNC samples with, and without the presence of DOM (Figure 5A). Similar to the increased mortality, there was a significant increase in pericardial and yolk sac edemas in the embryos exposed to $2000 \mathrm{mg} / \mathrm{L} \mathrm{L}-\mathrm{CNC}$, both with and without DOM present (Figure 5B and 5C).

This suggests that the chorion protects the embryo from direct exposure to CNs. This scenario is more representative of realistic situations than the removed-chorion experiments. The lack of differential toxicity with and without DOM suggest the addition of organic matter had little impact on the particle suspension and subsequent embryo exposure. Overall, these findings indicate little to no toxicity for L-CNC and L-CNF to zebrafish embryos.

Similarly, other studies have reported little acute toxicity or developmental effects in aquatic vertebrates for CNs. In zebrafish, Kovacs et al. (2010) reported that the LC50 of sulfated CNC was $>6000 \mathrm{mg} / \mathrm{L}$, and while hatching rates were observed to be slightly delayed over the first $54 \mathrm{~h}$ of exposure, the overall inhibitory concentration ( $\mathrm{IC}_{50}$ ) of hatching was still $>6000 \mathrm{mg} / \mathrm{L}$. A study conducted by Harper et al., (2016) examined a suite of other types of CNCs and CNFs with a range of surface chemistries (anionic, cationic and neutral surface charges) and their effects on embryonic zebrafish mortality. They concluded that $\mathrm{CNC}$ have an overall low toxicity to developing zebrafish with low incidences of mortality or developmental impairments at concentrations up to $1000 \mathrm{mg} / \mathrm{L}$ after 5 days of exposure. In CNF, they found mortality and some yolk sac pericardial edema in developing zebrafish starting at 250 and $5000 \mathrm{mg} / \mathrm{L}$, which varied dependent on the production method and surface functionalization (Harper et al. 2016). In rainbow trout, acute toxicity is also low; after exposure to sulfate functionalized CNCs, LC50 values ranged from $>1,000 \mathrm{mg} / \mathrm{L}$ to $>10,000 \mathrm{mg} / \mathrm{L}$, and no morphological or behavioral abnormalities were observed (Kovacs et al. 2010). 


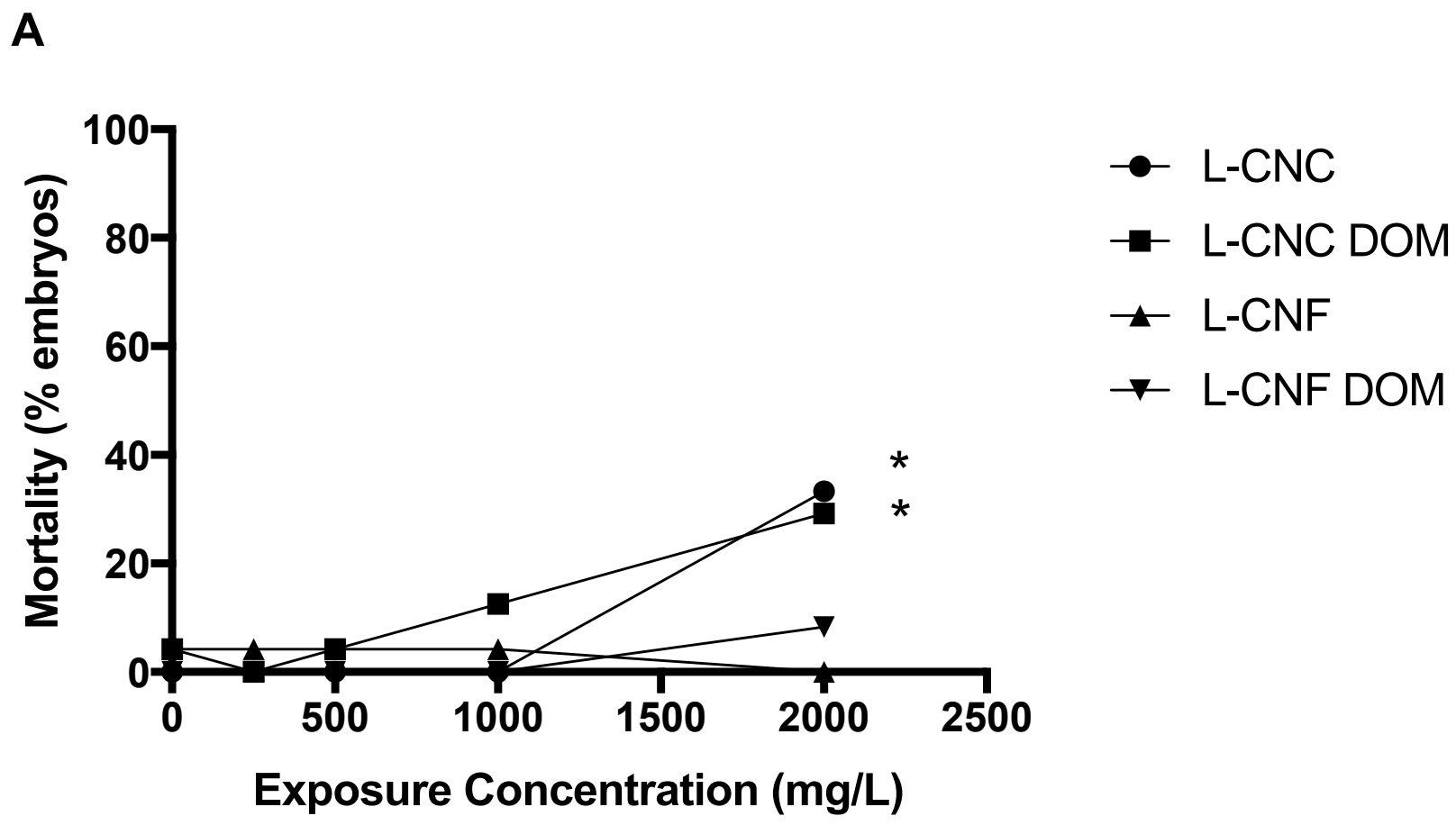

B

C
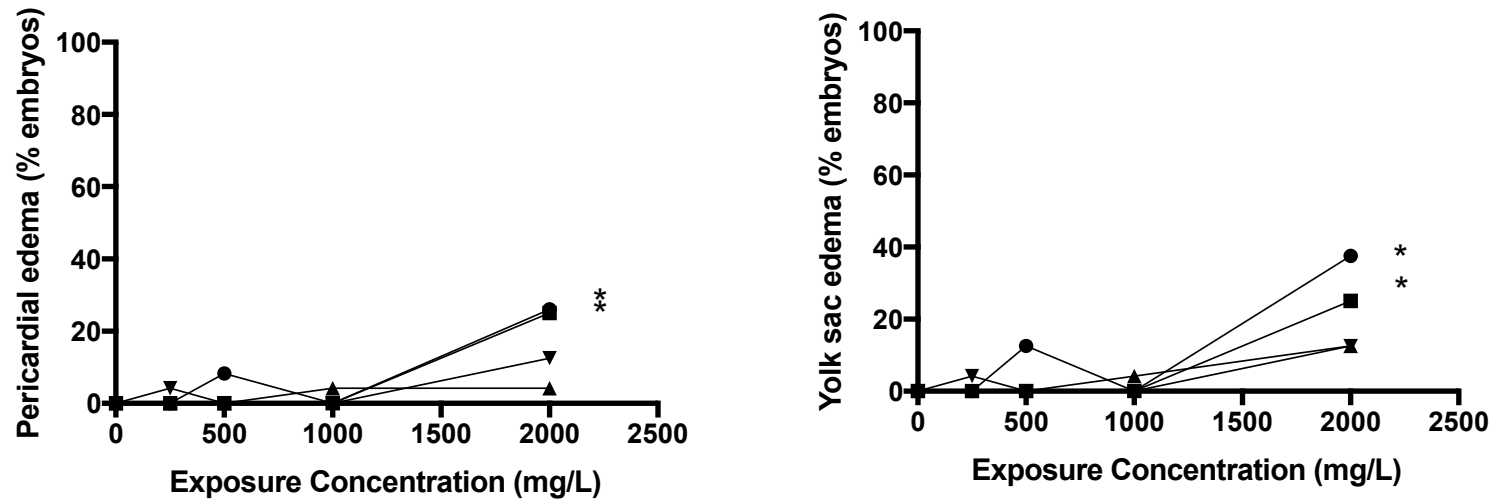

Figure 5. Exposure of dechorionated zebrafish embryos to L-CNC and L-CNF at $120 \mathrm{hpf}$, with 10 $\mathrm{mg} / \mathrm{L}$ dissolved organic matter (-DOM), or without organic matter. A) Mortality rate, B) Frequency of pericardial edema, and C) Frequency of yolk sac edema. * represents significant increase in response in comparison to $0 \mathrm{mg} / \mathrm{L}$ control ( $p<0.05$; Fisher's Exact test).

\section{Conclusions}

Together with published studies examining the effects of related and conventional substances, 
results demonstrate that L-CNC and L-CNF are relatively non-toxic. Data gaps, and areas of particular importance, such as occupational and environmental safety, were addressed in this study. In terms of occupational and human health safety, L-CNC was found to be less explosive than conventional cellulose dust and neither L-CNC nor L-CNF cause acute oral toxicity, or eye or dermal irritation. In the environment, these nanomaterials have a "low concern level" according to EPA Sustainable Futures classification paradigm and are not classified as hazardous under the GHS system (United Nations 2013).

Studies must always be interpreted in relation to real-world exposures; here we find effects only at very high concentrations that are not expected to be found in realistic scenarios. However, for the purposes of initial safety testing, it is practical to find these limits. Exposures that would lead to direct contact with substance (e.g. accidental dermal or eye contact by a worker during manufacturing) did not show any signs of irritation, even at the highest concentration of gel. Predictions of 'realistic' concentrations of $\mathrm{CN}$ in the environment have not been performed; however, realistic exposure values have been calculated for other nanomaterials produced in high volumes. In maximum emission scenarios, nanoscale titanium dioxide is predicted to be in surface water at $16 \mu \mathrm{g} / \mathrm{L}$ (Mueller and Nowack 2008) and silver present in river water at $0.32 \mu \mathrm{g} / \mathrm{L}$ (Blaser et al. 2008). The lowest NOEC determined in this study was $175 \mathrm{mg} / \mathrm{L} \mathrm{L-CNC}$ in algae; this is more than 1000 times higher than the maximum predicted emission values. For most studies, the LC50 is $>2000 \mathrm{mg} / \mathrm{L}$. Many standardized tests do not necessarily replicate real-life scenarios; since it is known that nanomaterials may bind readily to other particles, some flexibility in tests, including the addition of organic matter as conducted in the zebrafish assays, should be considered for certain types of materials.

At this point, it is still unclear what types of surface modifications will change the toxicity of nanomaterials. For lignin-coated CNs, these studies demonstrate the addition of a non-toxic lignin coating did not affect the non-toxic nature of cellulose and these data are supported by other published reports of CNs and conventional celluloses. While these studies build up a weight of evidence demonstrating safety of CNs, differences in manufacturing, purity, and surface chemistry currently require other forms to be individually tested, and preferably, to share the results in the public domain. This study demonstrates that both L-CNCs and L-CNFs have low potential for toxicity, especially at environmentally relevant exposure concentrations. L-CNC and L-CNF have potential to contribute to improvements in a number of sectors, and these data support the safe commercialization of lignin-coated cellulose nanomaterials.

The study of industrially relevant nanomaterials is essential to move forward safely with the commercialization of nanomaterials into products that can provide associated societal, human health, and environmental benefits. The goal of this study was to develop an industrially-relevant testing plan to gather toxicity data on lignin-coated $\mathrm{CNs}$ to assess the safety of this nanomaterial in advance of wide-scale market introduction and subsequent commercialization. The safety study presented here suggests these materials are highly benign. It is critically important to publish these types of data to reduce uncertainty related to commercialization of nanomaterials and provide important information on their similarities to the bulk or conventional forms of the material. Such 'scientifically negative findings' that demonstrate the safety of nanomaterials often go unpublished and are under-represented in the literature, forming a biased representation of safety. 


\section{Acknowledgements}

The authors of this paper would like to thank Dr. Natalie Girouard (Georgia Tech) and Debby Sherman of DS Imaging West Lafayette, IN for the TEM image and Kolby Hirth of the USDA Forest Service Forest Products Laboratory for the ICP-OES measurements, as well as Stacey Harper (Oregon State University) for design and conduct of zebrafish assays.

\section{Funding Sources}

This research was contracted by American Process Inc. for submission to regulatory agencies. All work was conducted independently of funding source.

\section{References}

Agenda 2020 Technology Alliance, 2016. Cellulose Nanomaterials Research Roadmap, Available at: http://www.agenda2020.org/technology-roadmaps.html.

Blaser, S.A et al. 2008. Estimation of cumulative aquatic exposure and risk due to silver: Contribution of nano-functionalized plastics and textiles. Science of the Total Environment, 390, pp.396-409).

BSI, 2007. Nanotechnologies - Part 2: Guide to safe handling and disposal of manufactured nanomaterials. Available at: http://www3.imperial.ac.uk/pls/portallive/docs/1/34683696.PDF

Catalán, J. et al., 2014. Genotoxic and immunotoxic effects of cellulose nanocrystals in vitro. Environmental and Molecular Mutagenesis, 56(2), pp.171-182.

Colombo, L. et al., 2015. Organ Distribution and Bone Tropism of Cellulose Nanocrystals in Living Mice. Biomacromolecules, 16(9), pp.2862-2871.

Dufaud, O. et al., 2011. Ignition and explosion of nanopowders: something new under the dust. Journal of Physics: Conference Series, 304, pp.012076-11.

ECHA, 2016. REACH: Information requirements. Available at: https://echa.europa.eu/regulations/reach/registration/information-requirements

Eckhoff, R.K. 2003. Dust Explosions in the Process Industries: Identification, Assessment, and Control of Dust Hazards. Gulf Professional Publishing.

EPA, 2012. Sustainable Futures/P2 Framework Manual. EPA-748-B12-001. EPA Office of Chemical Safety and Pollution Prevention.

Exec Order No. 13693, 80 FR 15869 (2015). Planning for Federal Sustainability in the Next Decade

FDA, 2006. Guidance for Industry: Summary Table of Recommended Toxicological Testing for Additives Used in Food. Available at: http://www.fda.gov/Food/GuidanceRegulation/GuidanceDocumentsRegulatoryInformation/Ingr edientsAdditivesGRASPackaging/ucm054658.htm

FDA, 2014. Guidance for Industry Considering Whether an FDA-Regulated Product Involves the 
Application of Nanotechnology, Available at:

http://www.fda.gov/downloads/RegulatoryInformation/Guidances/UCM401695.pdf.

Fernandes, T.F. et al., 2011. Preparation and characterization of novel biodegradable composites based on acylated cellulose fibers and poly(ethylene sebacate). Composites Science and Technology, 71(16), pp.1908-1913.

Fox, D.M. et al., 2012. Char-forming behavior of nanofibrillated cellulose treated with glycidyl phenyl POSS. Carbohydrate Polymers, 88(3), pp.847-858.

Fox, D.M. et al., 2013. Flame retarded poly(lactic acid) using POSS-modified cellulose. 1. Thermal and combustion properties of intumescing composites. Polymer Degradation and Stability, 98(2), pp.590-596.

Glor, M. \& Thunherr, P. 2015. Ignition Hazards Caused by Electrostatic Charges in Industrial Processes. Available at: http://www.thuba.com/display.cfm/id/102744/disp_type/display/filename/elektrostatik_e.pdf

Gupta, A. et al., (2017). Rheological and Thermo-Mechanical Properties of Poly(lactic acid)/LigninCoated Cellulose Nanocrystal Composites. ACS Sustainable Chemistry \& Engineering, (5), pp.1711-1720.

Harper, B.J. et al., 2016. Impacts of chemical modification on the toxicity of diverse nanocellulose materials to developing zebrafish. Cellulose, 23(3), pp.1763-1775.

Hove, E. L. \& King, S. (1979). Effects of pectin and cellulose on growth, feed efficiency, and protein utilization, and their contribution to energy requirement and cecal VFA in rats. The Journal of Nutrition, 109(7), 1274-1278.

Kotkoskie, L.A. et al., 1996. Qualitative investigation of uptake of fine particle size microcrystallinecellulosefollowingoraladministrationin. Journal of Anatomy, 189, pp.531-535.

Kovacs, T. et al., 2010. An ecotoxicological characterization of nanocrystalline cellulose (NCC). Nanotoxicology, 4(3), pp.255-270.

Kümmerer, K. et al., 2011. Biodegradability of organic nanoparticles in the aqueous environment. Chemosphere, 82(10), pp.1387-1392.

Leshine, S.B., 1995. Cellulose Degradation in Anaerobic Environments. Annual Review of Microbiology, 49, pp.399-426.

Moon, R.J., Schueneman, G.T. \& Simonsen, J., 2016. Overview of Cellulose Nanomaterials, Their Capabilities and Applications. JOM, 68(9), pp.2383-2394.

Motte, J.C. et al., 2015. Dynamic observation of the biodegradation of lignocellulosic tissue under solid-state anaerobic conditions. Bioresource technology, 191, pp.322-336.

Mueller, N.C. \& Nowack, B. 2008. Exposure modeling of engineered nanoparticles in the 
environment. Environmental Science and Technology, 42, pp.4447-4453.

Nelson, K. \& Retsina, T., 2014. Innovative nanocellulose process breaks the cost barrier. TAPPI JOURNAL, 13(5), pp.19-23.

Nelson, K. et al, 2015. U.S. Patent No. 9,187,865.

NIOSH, 2014. Current Strategies for Engineering Controls in Nanomaterial Production and Downstream Handling Processes, Cincinnati, $\mathrm{OH}$.

NIOSH, 1995. Occupational Safety and Health Guideline for Cellulose, Available at: http://www.cdc.gov/niosh/docs/81-123/pdfs/0110.pdf.

O'Connor, B., Berry, R. \& Goguen, R., 2014. Commercialization of Cellulose Nanocrystal (NCC) Production: A Business Case Focusing on the Importance of Proactive EHS Management. In M. Hull \& D. Bowman, eds. Nanotechnology Environmental Health and Safety. Elsevier, pp. 225246.

Oltjen, R. R., Sirny, R. J., \& Tillman, A. D., 1962. Effect of three levels of minerals and three levels of cellulose on the performance of sheep fed purified rations. Journal of Animal Science, 21(2), 302-305.

Ong, K.J. et al., 2014. Widespread Nanoparticle-Assay Interference: Implications for Nanotoxicity Testing. PLoS ONE. http://dx.doi.org/10.1371/journal.pone.0090650

OSHA, 1995. Occupational Safety and Health Guidelines for Cellulose. Available at: https://www.cdc.gov/niosh/docs/81-123/pdfs/0110.pdf

Paturi, G. et al. 2010. Cecal and Colonic Responses in Rats Fed 5 or 30\% Corn Oil Diets Containing Either 7.5\% Broccoli Dietary Fiber or Microcrystalline Cellulose. Journal of Agriculture and Food Chemistry, 58, pp.6510-6515.

Peng, Y. et al. 2012. Han, Drying cellulose nanofibrils: in search of a suitable method. Cellulose, 2012. 19(1): pp. 91-102.

Pitkänen, M. et al., 2014. Characteristics and safety of nano-sized cellulose fibrils. Cellulose, 21(6), pp.3871-3886.

Raemy, A. \& Loeliger, J., 1985. Self ignition of powders studied by high pressure differential thermal analysis. Thermochimica Acta, 85, pp.343-346.

Ronzon, T., Santini, F. \& MBarek, R., 2016. The Bioeconomy in the European Union in numbers. Facts and figures on biomass, turnover and employment. European Comission, Joint Research Centre, institute for Prospective Technological Studies, Spain.

Shatkin, J.A. 2012. Nanotechnology Health and Environmental Risks, $2^{\text {nd }}$ Edition. CRC Press, Boca Raton, FL, USA. 
Shatkin, J.A. \& Kim, B., 2015. Cellulose nanomaterials: life cycle risk assessment, and environmental health and safety roadmap. Environmental Science: Nano, 2, pp.477-499.

Shatkin, J.A. et al., 2014. Market projections of cellulose nanomaterial-enabled products- Part 1: Applications. TAPPI Journal, 13(5), pp.9-16.

Shatkin, J.A. et al., 2016. Toward cellulose nanomaterial commercialization: Knowledge gap analysis for Safety Data Sheets according to the Globally Harmonized System. TAPPI Journal, 15(6), pp.425-437.

Sundaravalli, O. E., Shurpalekar, K. S., \& Rao, M. N. (1971). Effects of dietary cellulose supplements on the body composition and cholesterol metabolism of albino rats. Journal of agricultural and food chemistry, 19(1), 116-118.

Truong, L., Harper, S.L. \& Tanguay, R.L., 2011. Evaluation of embryotoxicity using the zebrafish model. Methods in molecular biology, 691, pp.271-279.

United Nations, 2013. Globally harmonized system of classification and labelling of chemicals (GHS): Fifth revised edition 5 ed., New York and Geneva.

Vartiainen, J. et al., 2011. Health and environmental safety aspects of friction grinding and spray drying of microfibrillated cellulose. Cellulose, 18(3), pp.775-786.

WHO, 1998. Safety evaluation of certain food additives and contaminants: Microcyrstalline cellulose. WHO Food Additive Series 40. Geneva.

Wu, H.-C., 2010. Explosion Characteristics of Aluminum Nanopowders. Aerosol and Air Quality Research, 10, pp 33-42.

Wu, H.-C., Chang, R.-C. \& H-C, H., 2009. Research of minimum ignition energy for nano Titanium powder and nano Iron powder. Journal of Loss Prevention in the Process Industries, 22, pp 2124. 